\title{
SENSITIVITY OF TRANSPORT MODEL TO HYDRAULIC MODEL FOR FLOOD RISK ASSESSMENT OF ROAD INFRASTRUCTURES
}

\author{
CHIARA ARRIGHI(1), MARIA PREGNOLATO(2), RICHARD J. DAWSON(3) \& FABIO CASTELLI ${ }^{(1)}$ \\ (1) Department of Civil and Environmental Engineering, University of Florence, Florence, Italy, \\ e-mail chiara.arrighi@dicea.unifi.it \\ (2) Department of Civil Engineering, University of Bristol, Bristol, UK, \\ e-mail maria.pregnolato@bristol.ac.uk \\ (3) School of Engineering, Newcastle University, Newcastle, UK, \\ e-mail richard.dawson@newcastle.ac.uk
}

\begin{abstract}
Urban inundations cause large impacts to road infrastructures which are especially important during emergencies because the resilience of a community relies upon fast connection to shelters and critical facilities (e.g. hospitals, fire stations). Moreover, during riverine floods the inundation propagates in the urban environment mostly following the road network where most injuries and fatalities take place. This works aims at understanding the sensitivity of transport model and human vulnerability estimates to the resolution of the flood maps, which can be used to increase preparedness. Three different hydraulic approaches are compared: a quasi-2D model adopted for official flood hazard maps, a full 2D model (TELEMAC-2D) with a $30 \mathrm{~m}$ resolution (e.g. like common global DTMs) and a full 2D model with a mesh resolution able to capture single buildings and roads (LiDAR-derived $1 \mathrm{~m}$ resolution). Changes in time and distance between origin and destinations as a result of flooding are analyzed by coupling a network model with flood hazard, using a transport network disruption model. The vulnerability of pedestrians is based on a dimensionless stability threshold, based on subject characteristics and inundation parameters.

The methodology is applied to a district of Florence (Italy) placed at the crossing of two streams and in a crucial road junction for the area. The results in terms of road accessibility, service areas and citizens vulnerability are compared and discussed for the three different hydraulic approaches to provide support for decision makers and civil protection rescuers.
\end{abstract}

Keywords: flood risk, indirect impact, flood preparedness, pedestrians' vulnerability, drivers' vulnerability

\section{INTRODUCTION}

Flood risk in urban environments is expected to increase in future due to climate change effects and urbanization prospects (UNISDR, 2015). Urban mobility can be significantly affected by floods. On one hand, roads underpin mobility within urban areas and are especially important during emergencies because the resilience of a community relies upon fast connection to shelters, critical infrastructure and blue light services (Abdan and Zairul, 2017). On the other hand, most of the fatalities occur while driving vehicle or attempting to walk in floodwaters.

Flood preparedness is crucial to reduce impacts on lives, livelihoods and communities (UNISDR, 2015). However, limited information often exists on residual mobility, accessibility to critical infrastructures and risk to travelling vehicles or pedestrians. These aspects are mostly important to the Civil Protection (CP). Their main source of information is the flood hazard/risk zonation issued at district level, which usually identifies the inundation extent for assigned return period only.

This work integrates several aspects of urban mobility during floods, by combining flood models, transport models and vulnerability models in order to provide a comprehensive picture of flood consequences on the road network, useful to define management plans and coordinate emergency activities. The objectives of the work are:

1. the evaluation of residual road accessibility based on safety conditions for travelling vehicles;

2. the analysis of service areas for emergency operations;

3. the assessment of the number of residents at risk of being swept away on foot;

4. the sensitivity of the three points above with respect to the flood modelling approach. 
The methodology is applied to Galluzzo, a flood-prone district in the South of Florence (Central Italy). The work ultimately aims to provide civil responders with more advanced tools for planning and implementing emergency response operations, compromising between computational efforts and accuracy.

\section{METHOD}

2.1 Hydraulic models

In this work three different modelling approaches are compared. They differ in complexity, computational time and spatial resolution. The overarching aim is to identify the best compromise between modelling efforts and application to urban mobility for emergency planning.

The first hydraulic approach (HM1) is composed of two parts: the 1D unsteady flow model for the river and a quasi-2D storage cell model of the flood-prone area. This model is used for flood hazard zonation in the Arno River Basin (UOM Arno, 2015), to fulfill the requirements of the European Floods Directive 60/2007/EC. The computation of the flood propagation and corresponding water profile along the river(s) is performed through a standard solver of the 1D general equation of unsteady flow (i.e. continuity and momentum conservation equations). The quasi-2D hydraulic model for the flood plain consists of several storage areas whose effective geometry is estimated from a meter-scale LiDAR-derived Digital Terrain Model (DTM), where buildings are, by default, ignored. The continuity and momentum conservation equations are solved through an implicit 1D finite difference scheme for the river. The outflow from the river banks is modelled through a set of lateral weirs connecting river and flood plain. When the inundation starts, the quasi-2D module, governed by continuity and stage-storage relations, calculates the water levels from the volume stored in the cell. Flow between adjacent cells is described by a weir equation accounting for backwater effects. The details of the model construct and equations adopted in the HEC-RAS framework (for both 1D and quasi-2D modules) are described in Arrighi et al. (2013). The model output is open available as a GIS polygon shapefile identifying the inundated areas for assigned return period (e.g. high hazard for a return period equal or lower than 30 years).

The second hydraulic approach (HM2) consists in solving the shallow water (de Saint-Venant) equations using the finite-volume method and a computational mesh of triangular elements (Hervouet, 2007) with the TELEMAC-2D software. The mesh is generated in Blue Kenue specifying hard lines to properly identify the river levees with a resolution of $2 \mathrm{~m}$, while the mesh size is up to $30 \mathrm{~m}$ in open areas. The Blue Kenue interpolator tool allows the user to assign to each mesh node the elevation of the 30-m-resolution DTM. Buildings are again ignored in the mesh and in the elevation model. The model output is a 30 -m-resolution raster flood map depicting the maximum water depth reached during the whole simulation for each cell.

In the third approach (HM3), TELEMAC-2D is again used to solve the shallow water equations but the mesh is generated to account for buildings as waterproof blocks. Break lines are used to properly represent buildings with an assigned element size of $2 \mathrm{~m}$ at the building boundary to capture complex flows in the road network, but up to $8 \mathrm{~m}$ in open areas. The elevation of the mesh nodes is obtained by the LiDAR-derived DTM (1-m-resolution and $0.15 \mathrm{~m}$ of vertical accuracy). The model output is a 1 -m-resolution raster flood map representing the maximum water depth reached during the whole simulation for each cell.

Table 1 summarizes the main characteristics of the three hydraulic approaches and source geographic data (DTM) used for their implementation.

Table 1. Main characteristics of the hydraulic approaches for hazard evaluation.

\begin{tabular}{|c|c|c|c|}
\hline & HM1 & HM2 & HM3 \\
\hline SOLVER & $\begin{array}{l}\text { 1-D de Saint Venant } \\
\text { Equation for the river + } \\
\text { storage equation for } \\
\text { flood plain }\end{array}$ & $\begin{array}{c}\text { 2-D de Saint Venant } \\
\text { Equation }\end{array}$ & $\begin{array}{c}\text { 2-D de Saint Venant } \\
\text { Equation }\end{array}$ \\
\hline SOFTWARE & HEC-RAS & TELEMAC-2D & TELEMAC-2D \\
\hline DTM RESOLUTION & $1 \mathrm{~m}$ & $30 \mathrm{~m}$ & $1 \mathrm{~m}$ \\
\hline BUILDINGS & Not considered & Not considered & $\begin{array}{l}\text { As waterproof } \\
\text { blocks }\end{array}$ \\
\hline OUTPUT TYPE & Inundated area $\left({ }^{*}\right.$. shp $)$ & $\begin{array}{l}\text { Flood depth map } \\
\left({ }^{*} \text {.tiff }\right)\end{array}$ & $\begin{array}{l}\text { Flood depth map } \\
\left({ }^{*} \text {.tiff }\right)\end{array}$ \\
\hline
\end{tabular}

\subsection{Transport model}

A transport model is here used, firstly, to evaluate the vulnerability of the road network to the flood and, secondly, to assess accessibility issues.

The performance of a transport network can be assessed by evaluating the journey time (Smith and Blewitt, 2010). Transport models allow the mathematical modelling, or simulation, of transportation systems to inform the design process, by representing the stretches of roads (links, and their nodes), users, and users' routing. 
As a result of the inundation, changes in time and distance between origin and destinations are analysed by coupling a network model with the flood map. This evaluation consists of calculating the disruption to network links using a transport network disruption model developed by Pregnolato et al. (2016). The simulated floodwater depths are spatially overlapped with the road network, defining the impacted portion of roads for the analysis. A flood reduces speed, or stops entirely traffic flows according to the inundation depth. A disruption function Eq. [1], developed by Pregnolato et al. (2017), relates water depth to safe driving speed.

$$
V_{d}=0.0009 H^{2}-0.5529 H+86.9448
$$

where $H$ is the water depth $(\mathrm{m})$ and $V_{d}$ is the safe driving speed ( $\mathrm{km} /$ hour).

Roads are considered impassable (therefore closed) when the flood depth reaches $300 \mathrm{~mm}$, the depth at which a standard saloon or estate car is unable to operate (Gissing et al., 2016; Kramer et al., 2016). For the flooded scenarios, the network properties of a link (e.g. travelling speed) are modified according to this relationship, and traffic parameters recalculated for this perturbed state. Subsequently, journey travel time will increase in comparison with the baseline scenario. This also allows for calculating the service area. A service area is a polygon which identifies the region which can be reached by a vehicle in a given amount of time (Coles et al. (2017). Here we build the service area from the primary school of the analysed district in order to evaluate if it is possible to reach critical hotspots (e.g. hospitals) in 8 minutes, which is the response time of emergency service prescribed by Italian legislation.

\subsection{Vulnerability}

The vulnerability of the road network is evaluated considering two main aspects of mobility: by car and on foot. Three classes are defined to classify the vulnerability from low to high. The vulnerability class is obtained by dividing the flood depth to a critical threshold (low vulnerability ratio $<0.5$, medium vulnerability $0.5 \leq$ ratio $<1$, high vulnerability ratio $\geq 1$ ). For driving vehicles, the critical threshold is $300 \mathrm{~mm}$ (Pregnolato et al., 2017). A map with the maximum water depth reached in every cell during the event is used to extract $\mathrm{H}$. For each road link the maximum water depth over the link is extracted using Zonal statistics tool in QGIS.

For pedestrians the critical threshold $H_{c r p}$ is function of both water depth and velocity magnitude $U$ and of the height of the subject considered $H_{P}$

$$
H_{\text {crP }}=H_{P} \cdot \frac{0.29}{0.24+F r}
$$

where,

$$
F r=\frac{U}{\sqrt{g H}}
$$

$\mathrm{Eq}$ [2] is a regression curve obtained from a dimensional analysis and application to existing experimental data about people instability in floodwaters (Arrighi et al., 2019; Arrighi et al., 2017; Karvonen et al., 2000; Foster and Cox, 1973; Jonkman and Penning-Rowsell, 2008; Xia et al., 2014; Martínez-Gomariz et al., 2016). The evaluation of vulnerability for pedestrians is evaluated for each time step of the flood simulation in a post processing phase. Then the maximum temporal vulnerability is evaluated to obtain the worst-case scenario conditions. When the ratio between $\mathrm{H}$ and $H_{c r}$ is equal to 1 the loss of stability of the person is expected, possibly leading to potential injuries or casualties. In this application the average adult height in Italy, i.e. $1.7 \mathrm{~m}$, is selected to calculate the critical water depth.

\subsection{Exposure}

The population potentially exposed to dangerous conditions as pedestrians is evaluated based on census data. Exposure is here the number of people living in buildings surrounded by high/medium vulnerability conditions for pedestrians. Based on a $5 \mathrm{~m}$ buffer around each building the vulnerability class for pedestrians in adjacent roads is extracted and each building is assigned a vulnerability class. The number of people living in each vulnerability class is then summed up. For more details on the downscaling of population from census areas to buildings refer to Arrighi et al. (2019).

\section{CASE STUDY}

The method described in Section 2 is applied to a Southern district of the city of Florence (Central Italy) called Galluzzo. Galluzzo is located at the confluence of two streams called Ema and Greve, which have a 
catchment area of 121 and $283 \mathrm{~km}^{2}$ respectively. The district is a crucial traffic knot for accessing the city of Florence from the southern municipalities.

The areal extent of the hydraulic model is about $4.2 \mathrm{~km}^{2}$; the simulated Greve and Ema reaches are 4.2 and $8 \mathrm{~km}$ long respectively. With the hydraulic model HM2 and HM3 the computational mesh is composed by 106.825 and 453.112 elements respectively.

The population living inside the simulated area is around 12,000 inhabitants according to the most recent census data (2011).

A what-if scenario based on a rainfall event occurred in October 2013 in a boundary catchment has been selected as trigger of the inundation (Servizio Idrologico Regione Toscana, 2013). The 2013 actual rainfall is shifted $65 \mathrm{~km}$ in the northern direction to affect the Greve and Ema catchments to obtain the hydrologic boundary conditions. The rainfall event is composed by a sequence of two peaks with hourly maximum around $30 \mathrm{~mm}$ and $45 \mathrm{~mm}$ for Greve and Ema respectively, and cumulate rainfall of 635 and $780 \mathrm{~mm}$ for the 15 hours event. Precipitation peaks correspond to river discharge peaks of about $370 \mathrm{~m}^{3} / \mathrm{s}$ and $500 \mathrm{~m}^{3} / \mathrm{s}$ for Greve and Ema respectively. The highest peak of the Ema hydrograph corresponds to the 200 years return period, thus the official medium hazard zone (HM1) can be compared to the extent of the flood obtained by the 2D hydraulic approaches (HM2 and HM3).

\section{RESULTS}

Results are presented into three sections to make a comparison between the hydraulic approaches used. The first section (4.1) describes the results in terms of flood extent and inundation depths, the second (4.2) shows the results in terms of vulnerability of the road network for drivers and pedestrians, the third (4.3) shows the service areas evaluated. Most of the results are presented in maps with a focus on the Galluzzo district to be more readable, although this is only a portion of the study area.

\subsection{Flood hazard maps}

Figure 1 shows the flood hazard maps obtained with the three different hydraulic approaches. In the first panel (a) the official hazard zonation obtained with HM1 is shown. They are polygons identifying the areas prone to floods with a return period lower or equal to 30 years (high hazard, in orange) and with a return period between 30 and 200 years (medium hazard, yellow). This official hazard zonation is issued by the District of the Northern Apennines and is available for all the European territory as required by the Directive 2007/60/EC.

Panel (b) of Figure 1 shows the flood depth map obtained using HM2. Water depths in this portion of the study area are of the order of $0.5-1 \mathrm{~m}$ in the eastern side of the district and are of the order of 1.5-2 $\mathrm{m}$ in the western side of the district. The black line shows the edge of the hazard zonation of panel (a) superimposed on the flood depths. In terms of inundated areas, although the resolution of the DTM is different, the two hydraulic approaches HM1 and HM2 yield a very similar flood extension.

Panel (c) of Figure 1 shows the flood depth map obtained using HM3. Here the water depths are above 2 $\mathrm{m}$ in the western part of the district and around $1.5 \mathrm{~m}$ in the eastern area. Again, the inundation extent is pretty similar to the official hazard zonation for medium hazard.

Water depth differences between HM1 and HM2 are significant and show a pattern. In the western area flood depth differences between $\mathrm{HM} 2$ and $\mathrm{HM} 3$ are positive and of the order of $1.5 \mathrm{~m}$, locally up to $2.5 \mathrm{~m}$. In the eastern area the difference is negative, i.e. HM3 calculates higher flood depths, and of the order of $-0.25 \mathrm{~m}$, locally up to $-2 \mathrm{~m}$. This important difference in flood depth with the approaches HM2 and HM3 is caused by the terrain morphology, which is quite sharp in this area. The ground is particularly steeper in the eastern side of the district, thus the $30 \mathrm{~m}$ resolution DTM virtually raises the average terrain elevation with respect to the LiDARderived $1 \mathrm{~m}$ DTM. This effect is smoother in the western area since the terrain morphology is flatter.

Another consequence of these different terrain representations is in terms of flow velocity. In the district, flow velocity is significantly higher (of the order of $1-1.5 \mathrm{~m} / \mathrm{s}$ ) for HM2. Most of the urban area with the HM2 is subject to flow velocities around $1 \mathrm{~m} / \mathrm{s}$. In this comparison, both eastern and western district are characterized by higher flow velocities with HM2. Thus, Froude number (used to calculate the vulnerability of pedestrians) is higher for HM2.

\subsection{Vulnerability of road network and risk to population}

For the assessment of vulnerability, the information provided by HM1, i.e. the official zonation is not appropriate, since water depths and velocities are not available. The hazard zonation can be used in a conservative way by considering that all the roads inside the flood prone area are impracticable and all the people are potentially exposed without distinguishing between vulnerability classes.

Figure 2 shows the vulnerability of the road network considering the driving vehicles for HM2 an HM3. Each road link is classified with a vulnerability level, where the red color shows the roads which are considered impassable for passenger vehicles because the safety threshold of $0.3 \mathrm{~m}$ has been exceeded. Yellow road links are instead still practicable but with a reduced speed given by Eq [1]. In panel (a) and (b) of Figure 2 the 
vulnerability for travelling vehicles is obtained with the results of HM2 and HM3 respectively. Consistently with the lower water depths obtained with HM2, the vulnerability of panel (a) is slightly lower than in panel (b). In fact, with the HM2 the center of the district is still accessible from some road links, while with the HM3 all the area is cut off from the network. 


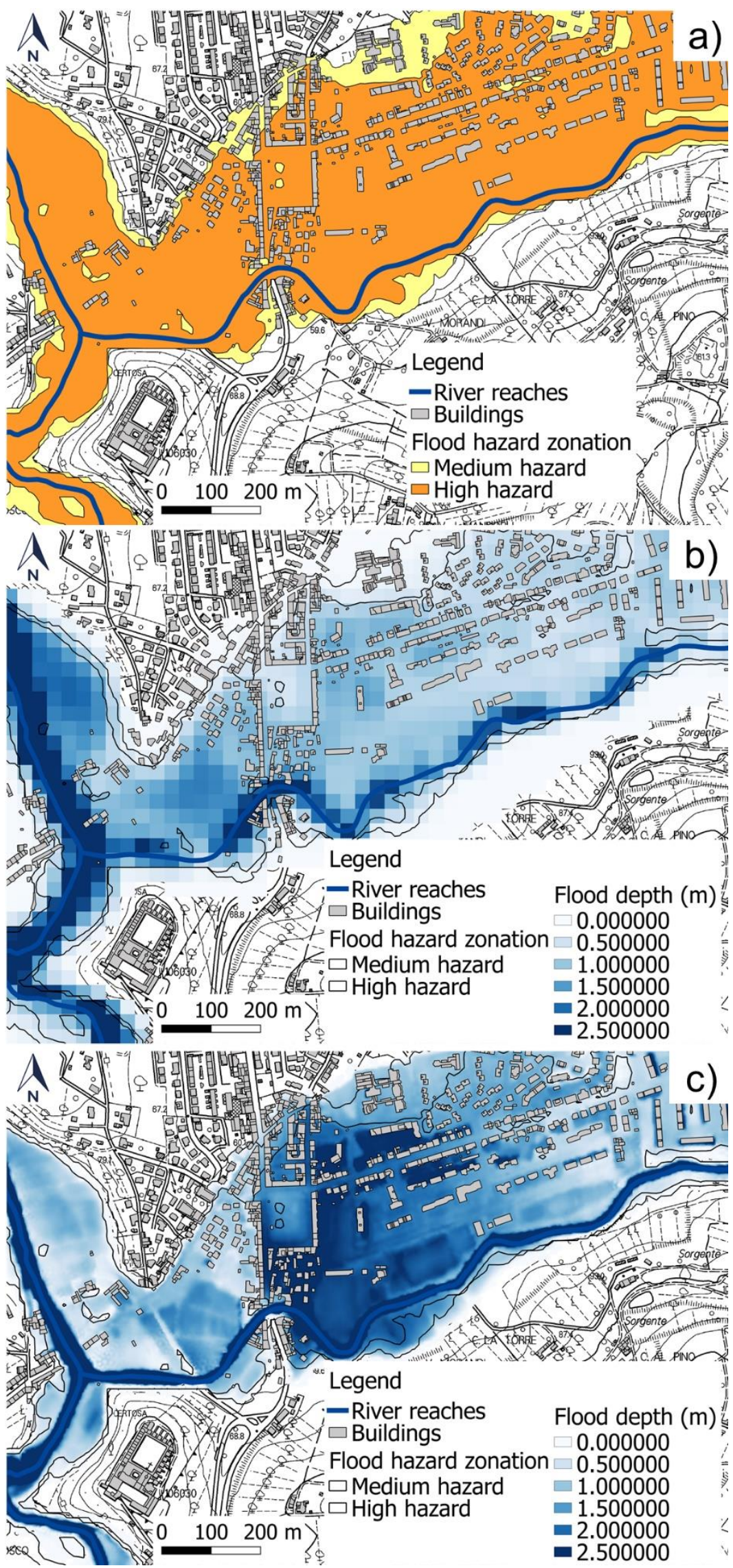

Figure 1. Flood hazard maps obtained for the same hydrologic scenario with the three modelling approaches: quasi-2d model for official zonation HM1 (a), full 2D model with 30 m resolution HM2 (b), full 2D model with 1 m resolution $\mathrm{HM} 3$ (c). 


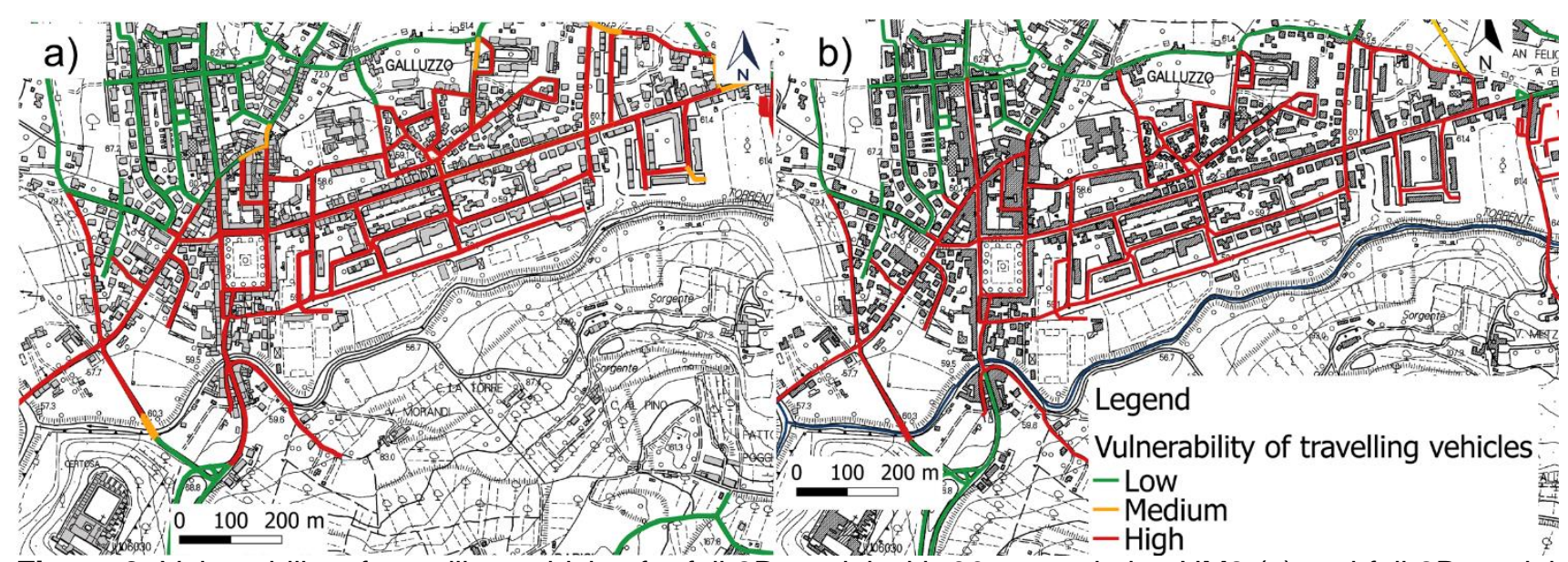

Figure 2. Vulnerability of travelling vehicles for full 2D model with $30 \mathrm{~m}$ resolution HM2 (a) and full 2D model with $1 \mathrm{~m}$ resolution $\mathrm{HM} 3(\mathrm{~b})$.

Figure 3 represents the vulnerability for pedestrians obtained by HM2 and HM3, panels (a) and (b) respectively. At a first sight, vulnerability of pedestrians with the two hydraulic approaches is pretty similar, despite the different DTM resolution. Here the main difference is due to the presence of buildings as waterproof blocks used in HM3. In fact, the presence of the buildings, clearly identifies preferential ways for flood propagation in roads, which are not well captured with the HM2 approach.

The vulnerabilities for pedestrians look similar in the two maps because the lower water depths in HM2 are compensated by the higher Froude number.

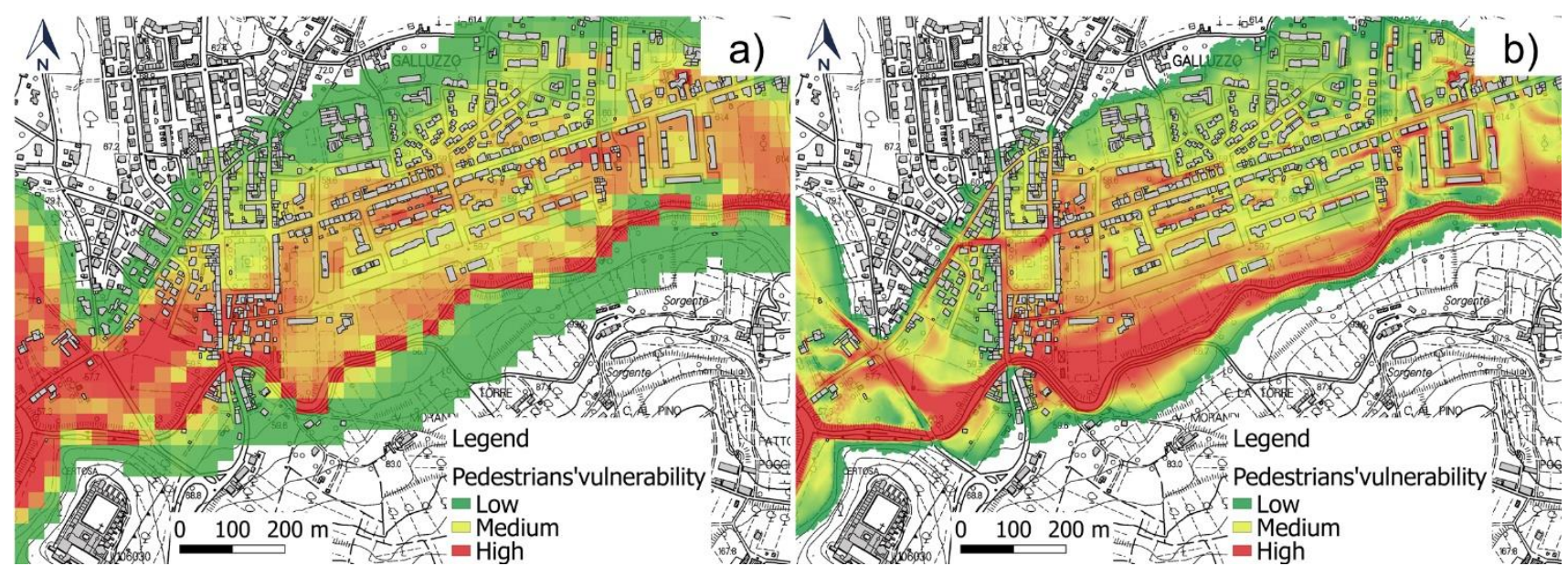

Figure 3. Vulnerability of pedestrians for full 2D model with $30 \mathrm{~m}$ resolution HM2 (a) and full 2D model with $1 \mathrm{~m}$ resolution HM3 (b).

In Table 2 the comparison between the three hydraulic approaches is presented in terms of population exposed to different vulnerability conditions for pedestrians for the whole study area, i.e. not limited to the portion of district shown in the map. With HM1 there is no distinction into vulnerability classes for pedestrians. The population living inside the medium hazard zone can be considered as potentially affected (8878 people).

With HM2 the overall number of inhabitants exposed to high vulnerability conditions is higher than with HM3, while people exposed to medium vulnerability is lower. The results obtained with HM2 are thus more conservative.

Table 2. Resident population at risk of being swept away as pedestrian with the three hydraulic approaches (*affected without info on vulnerability levels).

\begin{tabular}{cccc}
\hline $\begin{array}{c}\text { Pedestrians } \\
\text { vulnerability class }\end{array}$ & HM1 & HM2 & HM3 \\
\hline LOW VULNERABILITY & & 3546 & 3954 \\
MEDIUM VULNERABILITY & $8878^{*}$ & 2476 & 3638 \\
HIGH VULNERABILITY & & 6067 & 4497
\end{tabular}

TOTAL RESIDENTS 12089 


\subsection{Service areas}

Figure 4 depicts the service area calculated for the baseline scenario (panel a), i.e. no flooding, the HM2 approach (panel b1) and the HM3 approach (panel b2). As a starting point to calculate the service area, the primary school is selected. In the map the location of hospitals and fire and police stations is also shown. For the baseline scenario the service area is $110.5 \mathrm{~km}^{2}$, all the hospitals and emergency services can be reached in 8 minutes. For HM2, although the area that can be serviced shrinks to $38.6 \mathrm{~km}^{2}$, all the emergency centres can be reached. For HM3 the service area is dramatically reduced up to $4.1 \mathrm{~km}^{2}$ and none of the emergency hotspot can be safely reached in the time prescribed by law.

(a)
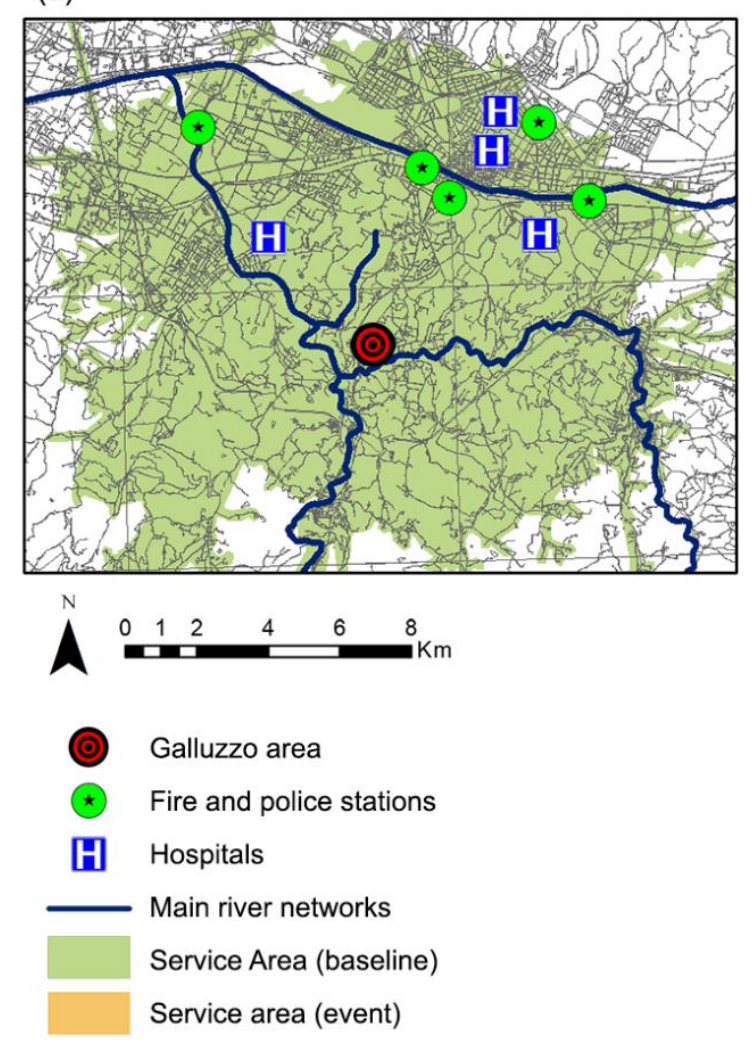

(b1) $30 \mathrm{~m}$ resolution

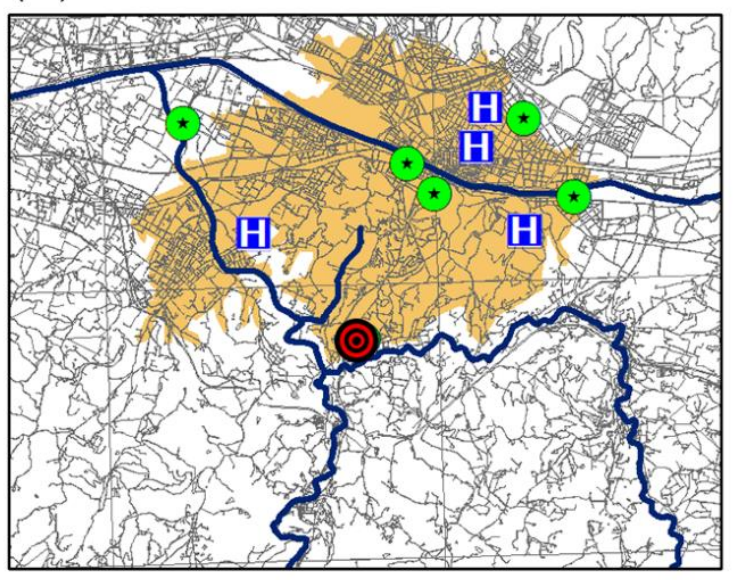

(b2) $1 \mathrm{~m}$ resolution

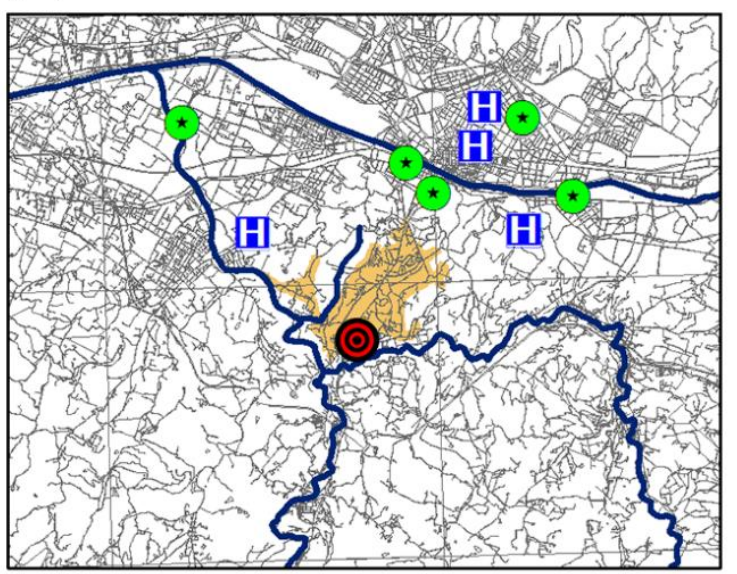

Figure 4. Service areas for the baseline (no flood event) (a) full 2D model with $30 \mathrm{~m}$ resolution HM2 (b1) and full 2D model with $1 \mathrm{~m}$ resolution $\mathrm{HM} 3(\mathrm{~b} 2)$.

\section{DISCUSSION AND CONCLUSIONS}

This paper analyzed crucial aspects of mobility during floods related to safety and accessibility: vulnerability of travelling vehicles and pedestrians and service area reduction. The above mobility aspects have been evaluated using three hydraulic approaches to describe the same hydrologic scenario. In the first, official hazard zonation issued by local district authority is adopted. Without the information on water depth and velocity only a conservative assessment for road vulnerability can be carried out, i.e. all the roads are impracticable for vehicles and for pedestrians inside the inundated zone, with no distinction on vulnerability levels.

With the second approach a 30-m-resolution DTM has been used to generate the mesh for a 2D model. In this case the vulnerability for driving vehicles is medium to high and around six thousand inhabitants are exposed to high vulnerability conditions for pedestrians. The service area built around the reference point in Galluzzo district is $38.6 \mathrm{~km}^{2}$ and all the emergency hotspots can still be reached during the emergency in 8 minutes. This because the roads in the north of Galluzzo resulted less impacted by the flood, thus still functional for travelling. This underlines the importance of the persistence of the performance of critical stretches of roads. With the third approach a 1-m-resolution DTM has been used to generate the mesh for a 2D model and buildings 
have been modelled as waterproof blocks. With this approach water depths are generally higher, almost all the flooded road network is impassable for vehicles and around 4500 inhabitants are exposed to high vulnerability conditions. The service area shrinks to $4.1 \mathrm{~km}^{2}$ and none of the hospitals can be reached with the prescribed time. This simulation, with the highest number of mesh elements takes around 72 hours to simulate a 35 hours hydrograph, while the HM2 model runs in about 12 hours. From the analyzed case study HM2 is more conservative for the vulnerability of pedestrians due to a compensation between flood depth and velocity, while HM3 is more conservative for the vulnerability of travelling vehicles and service area. The comparison does not allow to draw unequivocal conclusions on the suitability of these approaches for the assessment of mobility aspects without inundation data for validation which are not available for the study area. The morphological conditions of the area however suggest that the 1 -m-resolution DTM is more appropriate to describe the terrain since the 30-m-resolution altimetry tends to smooth the steepness of the area, thus modifying water depths and velocity. Although all the three hydraulic approaches identify similar flood prone areas, they strongly differ in flood parameters (water depth and velocity). In conclusion, official hazard zonation and the $30 \mathrm{~m}$ resolution hydraulic model can be good for large scale planning purposes, but for emergency operation and accessibility of crucial hotspots a higher resolution is needed (capable of describing road network and buildings) with validation of the model outputs.

\section{ACKNOWLEDGEMENTS}

Chiara Arrighi is supported by the Italian Ministry of Education, University and Research (PRIN2015$\mathrm{MICHe}$ ). Maria Pregnolato is supported by the Engineering and Physical Sciences Research Council (ESPRC) project "Resilience of national transport networks to flood-induced bridge failures" (Grant No. EP/N017064/1). Richard J. Dawson benefitted from funding from the EU FP7 project RAMSES: Reconciling Adaptation, Mitigation and Sustainable Development for Cities (Grant No. 308497) and the EPSRC project iBUILD: Infrastructure Business models, valuation and Innovation for Local Delivery (Grant No. EP/K012398/1). This research did not receive any further specific grant from funding agencies in the public, commercial, or not-forprofit sectors.

\section{REFERENCES}

Abdan, K., Zairul, A., 2017. Development of a disaster action plan for hospitals in Malaysia pertaining to critical engineering infrastructure risk analysis. Int. J. Disaster Risk Reduct. 21 (December 2016), 168-175. https://doi.org/10.1016/j.ijdrr.2016.12.002.

Arrighi, C., Brugioni, M., Castelli, F., Franceschini, S., Mazzanti, B. (2013). Urban microscale flood risk estimation with parsimonious hydraulic modelling and census data. Nat. Hazards Earth Syst. Sci. 13, 1375e1391. https://doi.org/10.5194/nhess-13-1375-2013.

Arrighi, C., Oumeraci, H., Castelli, F., (2017). Hydrodynamics of pedestrians' instability in floodwaters. Hydrol. Earth Syst. Sci. 21, 515-531. https://doi.org/10.5194/hess-21-515-2017.

Arrighi, C., Pregnolato, M., Dawson, R.J., Castelli, F. (2019). Preparedness against mobility disruption by floods. Science of the Total Environment 654 (2019) 1010-1022.

Coles, D., Yu, D., Wilby, R.L., Green, D., Herring, Z., (2017). Beyond 'flood hotspots': modelling emergency service accessibility during flooding in York, UK. J. Hydrol. 546, 419-436 https://doi.org/10.1016/j.jhydrol.2016.12.013.

Foster, D.N., Cox, R.J., (1973). Stability of children on roads used as floodways. Technical Report No. 73/13. Water Research Laboratory of the University of New South Wales, Manly Vale, Australia.

Gissing, A., Haynes, K., Coates, L., Keys, C., (2016). Motorist behaviour during the 2015 Shoalhaven floods. Aust. J. Emerg. Manag. 31 (2).

Hervouet, J.M., (2007). Hydrodynamics of free surface flows: modelling with the finite element method. John Wiley \& Sons, Ltd, Online 9780470319628 https://doi.org/10.1002/9780470319628.

Jonkman, S.N., Penning-Rowsell, E., (2008). Human instability in flood flows. J. Am. Water Resour. Assoc. 44 (5), 1208-1218. https://doi.org/10.1111/j.1752-1688.2008.00217.x.

Karvonen, R.A., Hepojoki, H.K., Huhta, H.K., Louhio, A., (2000). The Use Of Physical Models In Dam-Break Flood Analysis, Development of Rescue Actions Based on Dam-Break Flood Analysis (RESCDAM) (no. December: 57).

Kramer,M., Terheiden, K.,Wieprecht, S., (2016). Safety criteria for the trafficability of inundated roads in urban floodings. Int. J. Disaster Risk Reduct. 17, 77-84.

Martínez-Gomariz, E., Gómez, M., Russo, B., (2016). Experimental study of the stability of pedestrians exposed to urban pluvial flooding. Nat. Hazards 82 (2), 1259-1278. https://doi.org/10.1007/s11069-016-2242-z.

Pregnolato, M., Ford, A., Robson, C., Glenis, V., Barr, S., Dawson, R., (2016). Assessing urban strategies for reducing the impacts of extreme weather on infrastructure networks. Royal Soc. Open Sci. 3 (5), 1-15. 
Pregnolato, M., Ford, A., Wilkinson, S.M., Dawson, R.J., (2017). The impact of flooding on road transport: a depth-disruption function. Transp. Res. D 55, 67-81. https://doi.org/10.1016/j.trd.2017.06.020.

Servizio Idrologico Regione Toscana, (2013). Report eventi meteo-idrologici dei giorni 20 e 21 ottobre 2013.

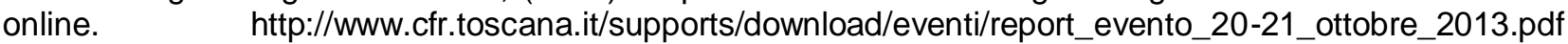
Accessed date: 18 May 2018.

Smith, J., Blewitt, R., (2010). Traffic Modelling Guidelines. Traffic for London, London (UK).

UNISDR, 2015. Sendai framework for disaster risk reduction 2015 - 2030. https://www. unisdr.org/we/inform/publications/43291.

UOM Arno (ITN002) Distretto Appennino Settentrionale (2015). Piano di Gestione del Rischio Alluvioni, online available at http://www.appenninosettentrionale.it/itc/?page_id=1512 last access 04-12-2019

Xia, J., Falconer, R.A., Wang, Y., Xiao, X., (2014). New criterion for the stability of a human body in floodwaters. J. Hydraul. Res. 52 (1), 93-104. https://doi.org/10.1080/00221686.2013.875073. 